ORIGINAL ARTICLE

\title{
The Football Association medical research programme: an audit of injuries in academy youth football
}

\author{
R J Price, R D Hawkins, M A Hulse, A Hodson
}

Br J Sports Med 2004;38:466-471. doi: 10.1136/bjsm.2003.005165

\begin{abstract}
Objectives: To undertake a prospective epidemiological study of the injuries sustained in English youth academy football over two competitive seasons.

Methods: Player injuries were annotated by medical staff at 38 English football club youth academies. A specific injury audit questionnaire was used together with a weekly return form that documented each club's current injury status.

Results: A total of 3805 injuries were reported over two complete seasons (June to May) with an average injury rate of 0.40 per player per season. The mean (SD) number of days absent for each injury was 21.9 (33.63), with an average of 2.31 (3.66) games missed per injury. The total amount of time absent through injury equated to about $6 \%$ of the player's development time. Players in the higher age groups (17-19 years) were more likely to receive an injury than those in the younger age groups (9-16 years). Injury incidence varied throughout the season, with training injuries peaking in January $(p<0.05)$ and competition injuries peaking in October $(p<0.05)$. Competition injuries accounted for $50.4 \%$ of the total, with $36 \%$ of these occurring in the last third of each half. Strains $(31 \%)$ and sprains $(20 \%)$ were the main injury types, predominantly affecting the lower limb, with a similar proportion of injuries affecting the thigh $(19 \%)$, ankle (19\%), and knee (18\%). Growth related conditions, including Sever's disease and OsgoodSchlatter's disease, accounted for $5 \%$ of total injuries, peaking in the under 13 age group for OsgoodSchlatter's disease and the under 11 age group for Sever's disease. The rate of re-injury of exactly the same anatomical structure was $3 \%$.

Conclusions: Footballers are at high risk of injury and there is a need to investigate ways of reducing this risk. Injury incidence at academy level is approximately half that of the professional game. Academy players probably have much less exposure to injury than their full time counterparts. Areas that warrant further attention include the link between musculoskeletal development and the onset of youth related conditions such as Sever's disease and Osgood-Schlatter's disease, the significant number of non-contact injuries that occur in academy football, and the increased rates of injury during preseason training and after the mid season break. This study has highlighted the nature and severity of injuries that occur at academy level, and the third part of the audit process now needs to be undertaken: the implementation of strategies to reduce the number of injuries encountered at this level.
\end{abstract}

See end of article for authors' affiliations

R J Price, The Footboll Association, Lilleshall Hall National Sports Centre, Lilleshall, Near Newport Shropshire TF10 9AT, UK; rob.price@thefa.com

Accepted 20 May 2003
F ootball is associated with relatively high incidences of injury. ${ }^{1-7}$ In the professional game in England, a player suffers, on average, 1.3 injuries a season and misses an average of 24 days of training and competition per injury. ${ }^{2}$

It has been hypothesised that the incidence of injury will vary according to the characteristics of the population being studied, ${ }^{8}$ including age and level of competition. ${ }^{9}$ Young footballers are thought to be at a higher risk of overuse injuries because of the immaturity of their musculoskeletal systems. ${ }^{3}$

The number of prospective injury studies in football is limited $^{14-7}$ and, in relation to injuries in youth football, is greatly restricted. ${ }^{10-12}$ Many of the studies available have been conducted on tournament play, which does not take into account training injuries. Injury rates vary from 0.5 per 1000 hours exposure ${ }^{13}$ to 29.9 per 1000 hours. ${ }^{14}$ However, in these studies, definition and recognition of injury is variable, as is the methodology used, and hence comparison is difficult.

To ensure the health and safety of young footballers, efforts must be made to prevent and control injuries. Before injuries can be prevented, we need to know the nature and severity of injuries that occur in youth football. There is a need to identify those groups most at risk of injury and determine the primary dependent and independent variables that will affect the rates of injury in this group of players. This study focused on injuries that occurred at English football club academies over a period of two seasons. Thirty eight academies were set up in 1998 to help to develop the next generation of elite footballers. Each academy was required to have a chartered physiotherapist on its staff to standardise the level of medical care received by the players.

An audit can be subdivided into four stages: collection of information, identification and description of findings, implementation of strategies to prevent injury based on the findings of the audit, and finally re-audit to assess the usefulness of the injury prevention strategies. ${ }^{15}$ The aim of this work was to implement the first two stages of the process by undertaking an epidemiological study of the injuries sustained in English football academies over two competitive seasons.

\section{METHODOLOGY}

Player injuries were prospectively reported from July 1999 to the end of May 2001 inclusive. Each of the 38 football academies committed themselves to the project, which involved all registered players from the ages of 9 to 19 years. Consent forms were completed for each player, by either the player himself or the parents if the player was under the legal age of consent. 


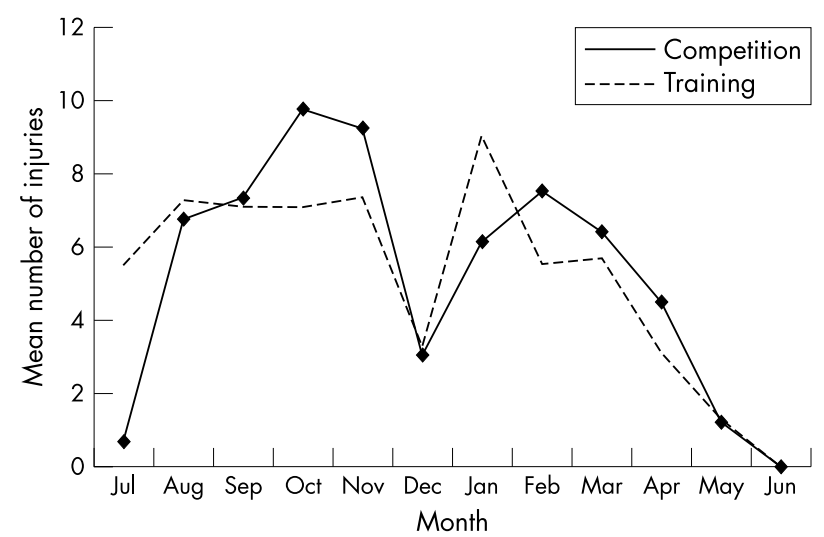

Figure 1 Mean injuries per academy per month in training and competition.

Injuries were annotated by the academy's medical personnel, following specific reporting guidelines agreed by the practitioners before the start of the project. The injury data were then transferred to an audit questionnaire designed specifically for this study. Categories included player information, injury information, classification of injury, supplementary information, and return from injury details.

Injury audit questionnaires for players who had returned to full training or competition during a particular week were returned together with a form indicating which players had been absent from activity and the number of days and competitive matches each had missed. Before the study, club medical staff attended a briefing day and were given guidance notes on how to complete the questionnaire. A recordable injury was defined as one that prevented the participant from training or playing for more than 48 hours, not including the day of injury. Injuries unrelated to football were not included, nor was any absence due to illness. Injuries acquired while on international duty were included because details of such injuries are generally reported back to club medical staff.

Data were analysed using the SPSS statistical software package (Chicago, Illinois, USA.). Descriptive and comparative data are presented. The $\chi^{2}$ significance test was used to investigate differences, and significance was accepted at the $\mathrm{p}<0.05$ level.

\section{RESULTS}

Of the 38 academies that started the study, 29 (76\%) completed injury records for the two seasons 1999/2000 and 2000/2001. A total of 4773 players were included in the audit, and, during the trial period, 3805 injuries were reported, giving an average injury rate of 0.40 per player per season.

Just over half the injuries were sustained during competition $(50.4 \%), 48.7 \%$ occurred during training, and no activity was specified for $0.9 \%$.

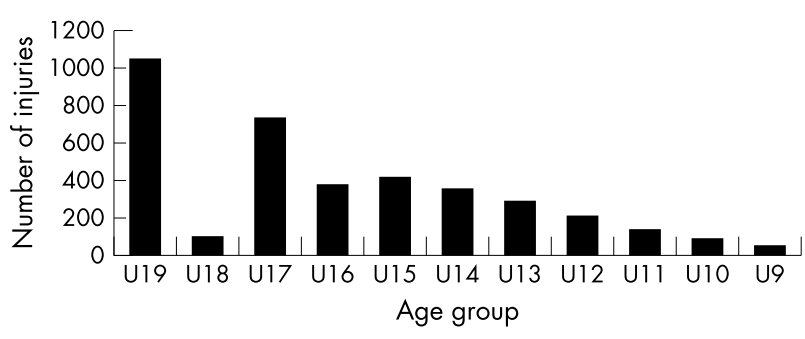

Figure 2 Injury incidence in relation to age group.

The injuries were retrospectively classified as slight, minor, moderate or, major depending on the length of time the player was prevented from playing and training because of the injury: two to three days, four to seven days, one to four weeks, and more than four weeks respectively. Table 1 shows the results.

Figure 1 shows the mean number of injuries sustained in training or competition at each academy per month. The number of injuries in training was highest in the months of August and January. The incidence of injuries in competition was highest in October $(\mathrm{p}<0.05)$. The difference in injury incidence between months was significant for both training and competition $(\mathrm{p}<0.05)$ December to January and July to August, the two periods after a break in activity.

The total number of days that players were absent over the two full seasons was 82929 (mean (SD) 21.9 (33.63) days per injury), and a total of 8803 matches were missed (2.31 (3.66) matches per injury).

Table 2 indicates injury incidence with respect to player position; defenders and midfielders were injured most often. Figure 2 indicates the percentage of injuries that occurred at each age level from under 9 to under 19. The incidence of injury increased linearly with age, except at the under 18 level. The figures for goalkeepers do not follow the same trend, as the injury rates do not increase linearly with age. The number of injuries occurring to goalkeepers at under 14, 15 , and 16 levels is similar to that of outfield players.

Table 3 gives the nature of injuries sustained during training and competition. Injuries classified as strains, sprains, contusions, or tissue bruising represented 66\% of all injuries. Most injuries were sustained on the dominant side $(54 \%$ v 35\%; $\mathrm{p}<0.05)$, and $90 \%$ of all injuries reported were to the lower extremity. Most thigh injuries were strains (79\%), and most of these were to the quadriceps or hamstrings (fig 3). Of the injuries to the knee, 28\% were ligament injuries, and $85 \%$ of these were to the medial collateral ligament (MCL). Injuries to the ankle were predominantly ligament strains $(72 \%) ; 83 \%$ of these involved the anterior talofibular ligament (ATFL).

Osgood-Schlatter's and Sever's disease accounted for 5\% of overall injuries. Figure 4 shows the age groups affected by these injuries. However, between the age of 11 and 13, these two conditions account for $13.8 \%$ of all injuries.

Table 1 Severity of injuries sustained during training and competition

\begin{tabular}{|c|c|c|c|c|c|c|}
\hline \multirow[b]{2}{*}{ Severity } & \multicolumn{2}{|c|}{ All injuries } & \multicolumn{2}{|c|}{ Competition injuries } & \multicolumn{2}{|c|}{ Training injuries } \\
\hline & No & $\%$ & No & $\%$ & No & $\%$ \\
\hline Slight & 380 & 10 & 180 & 8 & 183 & 10 \\
\hline Minor & 868 & 23 & 466 & 24 & 459 & 25 \\
\hline Moderate & 1659 & 44 & 912 & 48 & 842 & 46 \\
\hline Severe & 858 & 22 & 393 & 20 & 330 & 18 \\
\hline Not specified & 40 & 1 & & & & \\
\hline Total $^{*}$ & 3805 & 100 & 1951 & 100 & 1814 & 99 \\
\hline
\end{tabular}




\begin{tabular}{|c|c|c|}
\hline Position & No of injuries & Percentage \\
\hline Goalkeeper & 304 & 8 \\
\hline Defender & 1290 & 36 \\
\hline Midfielder & 1260 & 35 \\
\hline Attacker & 768 & 21 \\
\hline Total & 3622 & 100 \\
\hline
\end{tabular}

Table 4 highlights the location of injuries in competition and training; $75 \%$ of these were to the thigh, knee, ankle, groin, or lower leg. There was no significant difference in location of injury between competition and training.

Table 5 shows the mechanism of injury in both competition and training. Three categories, running, turning, and other non-contact activities, account for $34 \%$ of all injuries, and score highly in both competitive and non-competitive tables.

Of the injuries reported, 127 (3\%) were re-injuries. Of these, $72 \%$ were either strains or sprains, $6 \%$ were low back pain, and $5 \%$ were Osgood-Schlatter's injuries. Of the recurrent strains, 35\% involved the quadriceps, 33\% the hamstrings, and $20 \%$ the hip adductors. Of the recurrent sprains, $78 \%$ involved the ATFL and $20 \%$ were to the MCL of the knee.

Figure 5 highlights the time at which injuries occurred during competitive matches; $41 \%$ occurred in the first half, $50 \%$ in the second, and $36 \%$ in the last 15 minutes of the first and second halves collectively. A considerable proportion of injuries occurred in the warm up (4\%).

\section{DISCUSSION}

The definition of injury used follows that of many other authors $^{11617}$ and includes four subdivisions of severity. ${ }^{18-21}$ The inclusion of slight injuries (up to three days out of competition and training) allows calculations to be made about injuries that are reportable under the Reporting of injuries, diseases and dangerous occurrences regulations (RIDDOR). ${ }^{22}$ Reporting of injuries that prevented normal participation for less than 48 hours was deemed impractical because of the working practices of football academies.

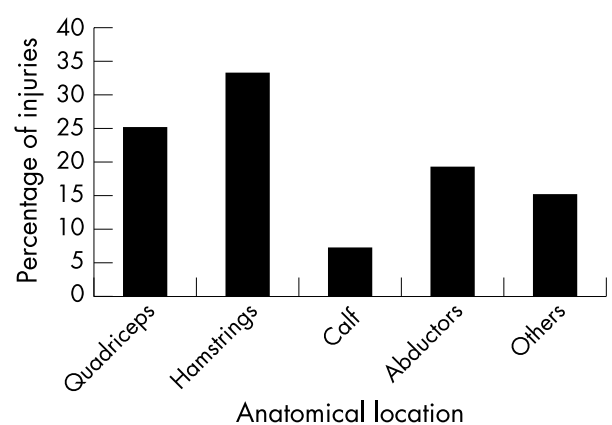

Figure 3 Anatomical location of strains of the leg.

When considering the findings of the audit, it is important to understand the academy games programme. Up to the age of 13, games are played with reduced team members-that is, seven against seven. After this age, games involving 11 against 11 are allowed. This may obviously alter the load on the players and hence affect the injury rates.

In professional football, the impact of injury on a club can be measured in terms of competitive matches missed and therefore costed against a player's wages or the performance of the team. In academy football, however, the impact of injury has to be considered from the point of view of the player's development and skill acquisition..$^{23}$ On average, each injury stopped the player participating in normal activities for 21.9 days, and each player was injured on average 0.40 times per season. This equates to the player missing about $6 \%$ of the season and therefore a large proportion of his development time. It has been hypothesised that a player must practise for slightly more than three hours a day for 10 years to achieve maximal skill development, ${ }^{24}$ a figure that would be hard to achieve if $6 \%$ of development time was lost.

The incidence of injury in professional football has been reported to vary over the course of a season, ${ }^{2}$ peak rates occurring after preseason training and after a mid season break. $^{1245}$ This study supports this theory, with sharp increases in injury rates seen in both August and January. However, exposure time has not been taken into account, therefore the reasons for these increases can only be hypothesised as being a result of resuming activity after rest, increased activity, a change in activity, or chance. In line with

Table 3 Nature of injuries sustained during training and competition

\begin{tabular}{|c|c|c|c|c|c|c|}
\hline \multirow[b]{2}{*}{ Nature of injury } & \multicolumn{2}{|c|}{ All injuries } & \multicolumn{2}{|c|}{ Competition injuries } & \multicolumn{2}{|c|}{ Training injuries } \\
\hline & No & $\%$ & No & $\%$ & No & $\%$ \\
\hline Muscular strain & 1141 & 31 & 558 & 29 & 583 & 33 \\
\hline Ligamentous sprain & 748 & 20 & 389 & 21 & 359 & 20 \\
\hline Muscular contusion & 299 & 8 & 211 & 11 & 88 & 5 \\
\hline Tissue bruising & 261 & 7 & 163 & 9 & 98 & 6 \\
\hline Tendinitis & 162 & 5 & 73 & 4 & 89 & 5 \\
\hline Fracture & 145 & 4 & 77 & 4 & 68 & 4 \\
\hline Low back pain & 117 & 3 & 51 & 3 & 66 & 4 \\
\hline Osgood-Schlatter's & 112 & 3 & 28 & 1 & 84 & 4 \\
\hline Periosteitis & 79 & 2 & 36 & 2 & 43 & 2 \\
\hline Inflammatory synovitis & 71 & 2 & 30 & 2 & 41 & 2 \\
\hline Sever's disease & 57 & 2 & 18 & 1 & 39 & 2 \\
\hline Meniscal tear & 48 & 1 & 28 & 2 & 20 & 1 \\
\hline Capsular tear & 32 & 1 & 17 & 1 & 15 & 1 \\
\hline Cut & 31 & 1 & 23 & 1 & 8 & 0 \\
\hline Other overuse & 23 & 1 & 14 & 1 & 9 & 1 \\
\hline Dislocation & 21 & 1 & 7 & 0 & 14 & 1 \\
\hline Ligament rupture & 19 & 1 & 11 & 1 & 8 & 0 \\
\hline Groin/abdominal hernia & 17 & 1 & 13 & 1 & 4 & 0 \\
\hline Other diagnosis & 305 & 6 & 152 & 6 & 153 & 9 \\
\hline Total & 3688 & 100 & 1899 & 100 & 1789 & 100 \\
\hline
\end{tabular}




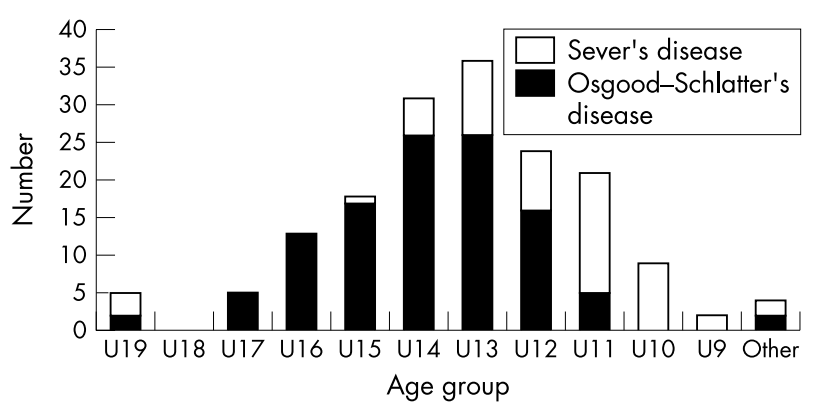

Figure 4 Number of injuries per age group due to Sever's disease and Osgood-Schlatter's disease.

the findings of the audit of injuries in professional football, ${ }^{2}$ it can be seen that injury rates increase sharply after the summer or mid season break, then decrease comparably until the next period of inactivity. It seems possible that, during these times, the players have not reached appropriate levels of fitness or their training programme is inappropriate or too intense to allow adaptation to occur.

Forwards were found to be less likely to be injured than either midfielders or defenders. Without knowing the positional make up of all the squads, it is impossible to calculate the significance of these findings, and further research should be undertaken to test the importance of these results.

Injury incidence was found to be highest in the oldest age group (under 19), with a linear reduction as age decreased. This could be due to increased competitiveness at both under 17 and under 19 levels, a difference in training loads as the players become full time at their clubs, the start of adolescence, ${ }^{25}$ or simply an increase in exposure. Again further research needs to be undertaken to ascertain this. It is interesting to note that an anomaly occurs at the under 18 level, where only $2 \%$ of injuries were seen. This is probably due to misreporting of the players' age group, as many under 18 s play under 19 s football (there is no under 18 category in competitive academy football). However, further research is needed to see if there is any anatomical or physiological reason for this discrepancy.

In comparison with studies on professional players, ${ }^{12-7}$ the amount of injury sustained in training was less in academies, with similar injury incidence in training and competition $(48 \% \vee 52 \%)$. This is probably due to the decreased frequency of training in academy football, with players up to the age of 17 usually only training twice a week and playing at weekends. However, the number of injuries incurred during training is still too high and the type of training needs to be looked at with regard to injury prevention. As might be expected, considerably fewer contusions occur in training than in competition, but the number of muscle strains is increased ( $33 \% v 29 \%$ ), which is a cause for concern. There remains a need to investigate the primary intrinsic and extrinsic factors previously associated with injury before preventive strategies can be implemented.

Some $90 \%$ of all injuries reported were to the lower limb; similar figures have been quoted in other injury incidence research articles. ${ }^{1-4}$ The most commonly injured area was the thigh, with the knee and then the ankle also figuring highly. A significant proportion of thigh injuries were strains (79\%). The reasons are probably multifactorial, including incomplete development of muscle in adolescents, the limited shock absorption of developing muscle, and the massive forces needed in football for kicking and acceleration. ${ }^{26}$ Another possible reason is the use of these muscles as stabilisers for the pelvis as opposed to the core abdominal muscles. ${ }^{27}$ Proportionally, $43 \%$ of these injuries were to the anterior thigh and $57 \%$ to the posterior thigh. Injuries to the knee accounted for $18 \%$ of the total, and $85 \%$ of these injuries were to the MCL. Again there are many reasons for this high incidence, including the anatomical position of the ligament and the extensive rotational forces in the game; it has been shown that a player experiences 1000 changes in playing activity during an average game. ${ }^{28}$ Further studies are needed to ascertain the effect of footwear on the level of injury to the MCL, to see if the rotational forces at the knee are altered with different types of footwear, and to determine the effectiveness of proprioceptive training as a preventive measure. The same factors with respect to injury to the MCL can also be applied to the ATFL; $19 \%$ of all injuries were to the ankle, and $83 \%$ of these were to the ATFL. Most injuries occurred on the dominant side. This is probably due to the greater involvement of that side in tackles, kicking, jumping, landing, and turning.

Osgood-Schlatter's disease and Sever's disease were associated with $5 \%$ of injuries, with the peak incidence being in the under 13 and under 14 age groups for OsgoodSchlatter's disease and the under 11 age group for Sever's disease. This corresponds to the beginning and end of the pubertal growth spurt in males. ${ }^{25}$ These findings indicate the importance to football clubs of identifying the onset of these

\begin{tabular}{|c|c|c|c|c|c|c|}
\hline \multirow[b]{2}{*}{ Location } & \multicolumn{2}{|c|}{ All injuries } & \multicolumn{2}{|c|}{ Competition injuries } & \multicolumn{2}{|c|}{ Training injuries } \\
\hline & No & $\%$ & No & $\%$ & No & $\%$ \\
\hline Thigh & 727 & 19 & 383 & 20 & 344 & 19 \\
\hline Ankle & 727 & 19 & 380 & 19 & 347 & 19 \\
\hline Knee & 664 & 18 & 358 & 18 & 306 & 17 \\
\hline Lower leg & 375 & 10 & 192 & 10 & 183 & 10 \\
\hline Groin & 351 & 9 & 172 & 9 & 179 & 10 \\
\hline Foot & 284 & 8 & 128 & 7 & 156 & 9 \\
\hline Lumbar spine & 162 & 4 & 81 & 4 & 81 & 5 \\
\hline Hip & 125 & 3 & 76 & 4 & 49 & 3 \\
\hline Toe & 51 & 1 & 32 & 2 & 19 & 1 \\
\hline Skull & 37 & 1 & 26 & 1 & 11 & 1 \\
\hline Shoulder & 35 & 1 & 14 & 1 & 21 & 1 \\
\hline Abdomen & 26 & 1 & 14 & 1 & 12 & 1 \\
\hline Sacroiliac joint & 26 & 1 & 12 & 1 & 14 & 1 \\
\hline Thumb & 19 & 1 & 4 & 0 & 15 & 1 \\
\hline Finger & 18 & 1 & 5 & 0 & 13 & 1 \\
\hline Other & 148 & 3 & 79 & 3 & 69 & 6 \\
\hline Total $^{*}$ & 3775 & 100 & 1956 & 100 & 1819 & 105 \\
\hline
\end{tabular}




\begin{tabular}{|c|c|c|c|c|c|c|}
\hline \multirow[b]{2}{*}{ Mechanism of injury } & \multicolumn{2}{|c|}{ All injuries } & \multicolumn{2}{|c|}{ Competition injuries } & \multicolumn{2}{|c|}{ Training injuries } \\
\hline & No & $\%$ & No & $\%$ & No & $\%$ \\
\hline Running & 736 & 19 & 290 & 16 & 446 & 23 \\
\hline Tackled & 585 & 15 & 398 & 22 & 187 & 10 \\
\hline Other (non-contact) & 291 & 8 & 107 & 6 & 184 & 9 \\
\hline Twisting/turning & 274 & 7 & 110 & 6 & 164 & 8 \\
\hline Tackling & 264 & 7 & 160 & 9 & 104 & 5 \\
\hline Kicked & 244 & 6 & 170 & 9 & 74 & 4 \\
\hline Collision & 244 & 6 & 170 & 9 & 74 & 4 \\
\hline Passing & 158 & 4 & 73 & 4 & 85 & 4 \\
\hline Shooting & 145 & 4 & 50 & 3 & 95 & 5 \\
\hline Stretching & 137 & 4 & 67 & 4 & 70 & 4 \\
\hline Landing & 115 & 3 & 64 & 4 & 51 & 3 \\
\hline Falling & 71 & 2 & 24 & 1 & 47 & 2 \\
\hline Hit by ball & 45 & 1 & 12 & 1 & 33 & 2 \\
\hline Jumping & 44 & 1 & 9 & 0 & 35 & 2 \\
\hline Diving & 35 & 1 & 8 & 0 & 27 & 1 \\
\hline Other (contact) & 33 & 1 & 16 & 1 & 17 & 1 \\
\hline Use of elbow & 14 & 0 & 13 & 1 & 1 & 0 \\
\hline Dribbling & 8 & 0 & 1 & 0 & 7 & 0 \\
\hline Heading & 3 & 0 & 1 & 0 & 2 & 0 \\
\hline Not specified & 362 & 10 & 127 & 7 & 235 & 12 \\
\hline Total $^{*}$ & 3808 & 99 & 1870 & 103 & 1938 & 99 \\
\hline
\end{tabular}

growth spurts to start early effective treatment and management or even prevention of these injuries.

The most important mechanism of injury seen in the study was running. Unfortunately this was not subdivided further to take into account the stage of the running cycle, the speed of running, or whether the player was accelerating or decelerating. However, the incidence of injury in noncompetition was $23 \%$, highlighting that this as an area that could benefit from further investigation to try to reduce the mechanisms of non-contact injury incidence in football.

Fatigue, both neural and muscular, has been hypothesised as a causative factor for injury in football. ${ }^{29}$ This needs consideration when the time of injury during competitive football is investigated. In line with previous studies, ${ }^{12}$ the incidence of injury increased as each half progressed, with most occurring in the last 15 minutes of each half. In academy football, this pattern seems to be heightened, with a less noticeable fall after half time, and a large number of injuries being documented in the mid third of each half as well as the last 15 minutes $(p<0.05)$. More injuries occurred in the second half of matches than the first ( $50 \% v 41 \%)$. The reasons are again probably multifactorial, including the previously mentioned neuromuscular fatigue, but the immaturity of the musculoskeletal and physiological systems of the players must also be considered.

Re-injuries have previously been shown to make up $17 \%$ of documented injuries. ${ }^{1}$ In this study, however, the re-injury rate was relatively low at $3 \%$; most were strains and sprains,

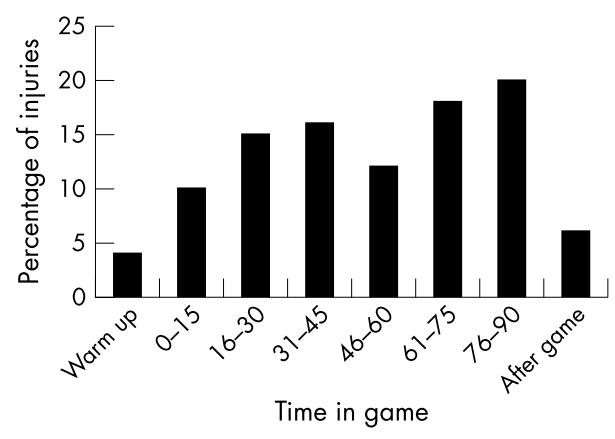

Figure 5 Injury occurrence at different times in the game. which may indicate inadequate rehabilitation after injury or a premature return to activity. Overall, this low rate of reoccurrence is promising and possibly shows that the pressures to return these young players to competition are not as intense as in the professional game and that coach education and player compliance are greater at this level.

It is expected that the epidemiological data obtained from this study will not only aid academies with adherence to current health and safety legislation but also provide insight into the nature and severity of injuries, highlight the causative factors of injury, and provide details of the consequences of injury to player development.

It is also possible that some injuries are prevented by an effective screening programme used by academies before the start of each season or before the player becomes full time. Further research into this area may indicate the need for increased screening from an appropriately qualified medical practitioner. At present, most screening is performed by orthopaedic surgeons; however, sports medicine practitioners may be more suited to carry out this role.

This first article on injury rates in academy football has highlighted a number of areas that warrant further research. One of the biggest omissions from the study is the investigation of exposure time in relation to injury. This is needed to ascertain which age groups are most susceptible to injury, and measures have been put in place to obtain this information for future analysis. Age related injuries need to be examined further. Subdivision of the age groups may aid analysis of incidence and type of injury in different age ranges. Other areas that warrant further investigation

\section{Take home message}

- A large proportion of a player's development time can be missed through injury.

- Strategies need to be implemented to try to reduce the number of strains, sprains, and non-contact injuries that are prevalent in academy football.

- Further research is needed to evaluate the exposure to injury at youth level. 
include the prevention and rehabilitation of muscular strains and ligament sprains, the high incidence of injuries in noncompetition running, and the incidence and treatment of specific growth related dysfunctions such as OsgoodSchlatter's disease and Sever's disease. Finally the data from this study should be combined with the research being carried out in academies on musculoskeletal growth and maturation to see if a link can be found between level of maturation and growth and susceptibility to injury.

\section{ACKNOWLEDGEMENTS}

We thank the medical practitioners at the football club academies for their help and commitment during the completion of this project.

\section{Authors' affiliations}

R J Price, R D Hawkins, M A Hulse, A Hodson, The Football Association, Lilleshall, UK

\section{REFERENCES}

1 Hawkins RD, Fuller CW. A prospective epidemiological study of injuries in four English professional football clubs. Br J Sports Med 1999;33:196-203.

2 Hawkins RD, Hulse MA, Wilkinson C, et al. The association football medical research programme: an audit of injuries in professional football. $\mathrm{Br} J$ Sports Med 2001;35:43-7.

3 Schmikli SL, Bol E. Actions in youth soccer games causing injuries. Med Sci Sports Exerc 1995;27:229-34.

4 Anglietti P, Zaccherotti G, De Biase P, et al. Injuries in soccer: mechanism and epidemiology. In: Renstrom PAFH, ed. Clinical practice of sports injury prevention and care. Oxford: Blackwell Scientific Publications, 1994:277-84.

5 Lewin G. The incidence of injury in an English professional soccer club during one competitive season. Physiotherapy 1989;75:601-5.

6 McGregor JC, Rae A. A review of injuries to professional footballers in a premier football team (1990-93). Scott Med J 1995;40:16-18.

7 McPherson K. Injuries to professional football players. Oxford: Department of Medicine and General Practice, University of Oxford, 1985.

8 Inklaar H. Soccer injuries II: aetiology and prevention. Sports Med 1994; 18:81-93.
9 Inklaar H. Soccer injuries I: incidence and severity. Sports Med 1994; 18:55-73.

10 Nilsson S, Roaas A. Soccer injuries in adolescents. Am J Sports Med 1978;6:358-61.

11 McCarroll JR, Meaney C, Sieber JM. Profile of youth soccer injuries. Phys Sportsmed 1984; 12:113-17.

12 Dvorak J, Junge A. Football injuries and physical symptoms. A review of the literature. Am J Sports Med 2000;28:S3-9.

13 Sullivan JA, Gross RH, Grana WA. Evaluation of injuries in youth soccer. Am J Sports Med 1980;8:325-7.

14 Schmidt-Olsen S, Bunemann KH, Lade V, et al. Soccer injuries of youth. Br J Sports Med 1985; 19:161-4.

15 Van Mechelen W, Hobil H, Kemper HCG. Incidence, severity, aetiology and prevention of sports injuries. A review of concepts. Sports Med 1992;14:82-99.

16 Vinger PF. Sports injuries. Littleton, MA: PSG Publishing Co, 1981

17 Council of Europe. Sport for all: sports injuries and their prevention. Oosterbeek, The Netherlands: Council of Europe, 1989.

18 Ekstrand J. Soccer injuries and their prevention. LinkopingUniversity Medical Dissertations. Linkoping, Sweden: Linkoping University, 1982: No 130.

19 Engstrom B, Forssblad M, Johansson C, et al. Does a major knee injury definitely sideline an elite soccer player? Am J Sports Med 1990;18:101-5.

20 Nielsen AB, Yde J. Epidemiology and traumatology of injuries in soccer. Am J Sports Med 1989;17:803-7.

21 Sandelin J, Santavirta S, Kiviluoto O. Acute soccer injuries in Finland in 1980. Br J Sports Med 1985; 19:30-3.

22 Reporting of injuries, diseases and dangerous occurrences regulations 1995. London: HMSO, 1995;SI 1995:no 2023.

23 Charness N. Aging and human performance. London: John Wiley and Sons Limited, 1985.

24 Ericsson K, Anders L, Charness Neil. Expert performance: its structure and acquisition. Am Psychol 1994;49:725-47.

25 Malina RM, Bouchard C. Growth, maturation and physical activity. Leeds: Human Kinetics Europe Limited, 1991

26 Hall S. Basic biomecanics. London: McGraw-Hill Publications, 1999.

27 Gibbons SGT, Comerford MJ. Strength versus stability. Part I. Concepts and terms. Orthopaedic Division Review 2001 Mar/Apr:21-7.

28 Reilly T, Thomas T. A motion analysis of work rate in different positional roles in professional football match play. Journal of Human Movement Studies 1976:2:87-97.

29 Davis JM, Bailey SP. Possible mechanisms of central nervous system fatigue during exercise. Med Sci Sports Exerc 1996;29:45-57. 